\title{
Analysis of different levels of viral suppression in HIV-1 patients after antiviral treatment
}

\section{LISHA DING ( $\nabla$ hyjx1982@126.com )}

Hunan Provincial Center for Diseases Control and Prevention https://orcid.org/0000-0002-5787-1435 XI CHEN

Hunan Provincial Center for Diseases Control and Prevention

\section{Research article}

Keywords: HAART; influencing factors; suppression; viral loads; test \& treat

Posted Date: July 29th, 2019

DOI: https://doi.org/10.21203/rs.2.12032/v1

License: (c) (i) This work is licensed under a Creative Commons Attribution 4.0 International License. Read Full License 


\section{Abstract}

Background Though highly active antiretroviral therapy (HAART) has brought the tremendous benefits to the HIV patients, there are still some patients with low HIV replication after treatment. This study investigated the influencing factors of different levels of viral suppression in HIV-infected patients in Central China. Methods A total of 4424 HIV-infected patients treated in 2016 from Hunan Province were enrolled and divided into 5 groups according to the level of virus replication, characteristics and clinic indicators were analyzed. Results There were 3871 cases (87.5\%) who maintained the viral loads under 200 copies/mL after treatment, 261 cases (5.9\%) with repeated test results, 57 cases (1.3\%) had sustained low-level replication of virus, and 235 cases (5.3\%) had long-term high-level replication of virus. Not surprisingly, the trend of CD4 cell counts growth were correlated with the trend of viral loads declination. Age, transmission mode, CD 4 cell counts baseline, the interval between test and treat and the final statues between 5 groups were significant differences $(P<0.05)$. Compared with low-level replication group, patients with clinical phase I were more likely be in complete supression group than those with clinical phase IV; Patients transmitted by hetero sex were more likely to be with repeated viral loads than those transmitted by blood transfusion or contaminated blood products or mother-to-child. If we define viral loads always less than 200 copies/mL as the criterion for positive treatment, CD 4 cell counts baseline under $500 \mathrm{n} / \mu \mathrm{L}$ and co-infected with HBV were independent risk factors for high HIV-1 replication, but young and test \& treat were independent protective factors for viral suppression. Conclusions Early treatment is more effective in inhibiting viral replication, but screening for incomplete viral supression patients should be a routine practice in the management and control of HIV infection.

\section{Background}

Highly active antiretroviral therapy (HAART) is the most effective method to treat AIDS at present and has been carried out for more than ten years in Hunan, central region in China. It can effectively inhibit the replication of HIV virus in patients, rebuild the immune system of the body, and improve the quality of life of patients ${ }^{[1-4]}$. Generally speaking, after 3 to 6 months of treatment, the level of HIV RNA in the plasma of patients can be reduced to less than 20 copies/ $\mathrm{mL}^{[5-6]}$. The third edition of the National Guidelines for Diagnosis and Treatment of China (2015 edition) adopted the criterion of effective treatment for viral suppression $<200$ copies $/ \mathrm{mL}$, the opposite is regarded as failure. But the current standard line for drug resistance detection in China is viral load $\geq 1000$ copies $/ \mathrm{mL}$. As a matter of fact, after long-term treatment, a small number of HIV patients' virual loads have been maintained at 200-999 copies/mL, that is, long-term low-level replication. The mechanism and influencing factors are still unclear, leading to clinical difficult to determine the prognosis. In this study, the target patients were divided into 5 groups by retrospective analysis of different levels of viral suppression after treatment, and the factors leading to this situation were evaluated by comparing various basic data and clinical data among the groups

\section{Materials And Methods}

\section{Samples}


From January to December 2016, there were 5099 newly treated HIV-1 patients in Hunan province, of which 675 were missing follow-up data, and the remaining 4424 were included in the study. Virological indicators, or viral loads was the main criteria for judging the therapeutic effect, which accorded with the third edition of the Guidelines for Diagnosis and Treatment(2015 edition). All the values of VL were $<200$ copies/mL after 6-12 months of treatment were selected as group 1; low trend in first and high trend in late with the first test value $\geq 200$ copies $/ \mathrm{mL}$ and the continues $<200$ copies $/ \mathrm{mL}$ were group 2 , the opposite as group 5; all the values of VL were between 200-999 copies/mL was group 3; all the values of VL were $\geq 1000$ copies/mL as group 4 .

\section{Statistical analysis}

Statistical analysis was performed with SPSS for Windows version 21.0 (SPSS, Chicago, IL, USA). Continuous variables were tested using Student's $t$-test. Categorical variables were analyzed using the $x^{2}$ test. Risk factors were analyzed by multinomial regression and multivariate regression. Statistical significance was denoted as $P<0.05$.

\section{Results}

\section{Demographic characteristics of the target patients}

Samples were collected from 4424 HIV-infected patients treated in 2016. Among these, 3396 (76.8\%) were male and 1028 (23.2\%) were female. The mean age was $43.3 \pm 15.4$ years. Transmission modes were intravenous drug use $(60,1.4 \%)$ and sexual transmission $(4038,91.3 \%)$. HIV-1/TB dual infection, HIV-1/HBV dual infection, and HIV-1/HCV dual infection were found in 210 (4.7\%), 144 (3.3\%), and 56 (1.3\%) patients, respectively. There were 449 (10.1\%) patients treated with LPV/r initially, 3967 (89.7\%) patients adhered the "test \& treat" policy, and $50(1.1 \%)$ had died up to now. Demographic characteristics of HIV-infected patients enrolled in this study are summarized in Table 1.

\section{The immunologic response among 5 groups}

The immunologic indicators of 4424 target patients changed every year. In 2017, the average CD4 cell counts in every group were $370.4 \pm 235.4 \mathrm{n} / \mu \mathrm{L}, 282.9 \pm 196.3 \mathrm{n} / \mu \mathrm{L}, 295.3 \pm 179.6 \mathrm{n} / \mu \mathrm{L}, 270.7 \pm 183.4 \mathrm{n} /$ $\mu \mathrm{L}$ and $327.2 \pm 230.0 \mathrm{n} / \mu \mathrm{L}$, respectively $(F=13.218, p=0.000)$. While in 2018 , the average CD 4 cell counts in every group were $431.4 \pm 288.5 \mathrm{n} / \mu \mathrm{L}, 369.3 \pm 219.9 \mathrm{n} / \mu \mathrm{L}, 356.4 \pm 221.7 \mathrm{n} / \mu \mathrm{L}, 323.0 \pm 261.6 \mathrm{n} / \mu \mathrm{L}$ and $310.5 \pm 235.9 \mathrm{n} / \mu \mathrm{L}$, respectively $(F=10.476, p=0.000)$. Except group5, the average counts of $\mathrm{CD} 4^{+} \mathrm{T}$ cell in ART patients improved obviously, especially in group 1. The rising trends are showed in Fig 1.

\section{Multinomial analysis}

Risk factors for different level of HIV-1 replication were analyzed by multiple logistic regression analysis.

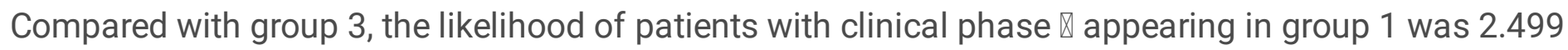
times that of those with clinical phase $\otimes(O R=2.499, P=0.033)$. Males were 2.056 times more likely to be 
in group 2 than females $(O R=2.056, P=0.043)$; patients with lower CD4 cell counts baseline $(<200 \mathrm{n} /$ $\mu \mathrm{L})$ were 4.522 times more likely to be in group 2 than those loosing CD4 cell results $(O R=4.522, P=$ 0.011). Patients transmitted by hetero sex were 5.494 times more likely to be in group 5 than those transmitted by blood transfusion or contaminated blood products or mother-to-child $(O R=5.494, P=$

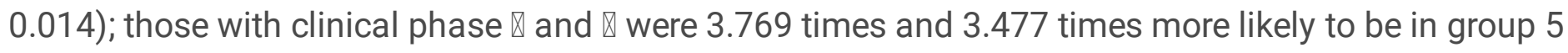
than those with clinical phase $\otimes(O R=3.769, P=0.013 ; O R=3.477, P=0.028)$, respectively.

\section{Multivariate analysis}

Risk factors for positive HIV-1 inhibition were analyzed by multiple logistic regression analysis. Positive suppression was defined as viral loads keeping $<200 \mathrm{copies} / \mathrm{mL}$ after treatment. Sex, age, transmission modes, HBsAg, anti-HBs, HBeAg, anti-HBe and anti-HBc were used for univariate analysis. Sex, age, transmission mode, CD4 cell counts baseline, marital status, dual infection, initial regimen, and test \& treat were associated with positive suppression $(P<0.05)$. After multivariate analysis, CD 4 cell counts baseline under $500 \mathrm{n} / \mu \mathrm{L}$ and co-infected with HBV were independent risk factors for high HIV-1 replication, but young age and test $\&$ treat were independent protective factors for viral suppression. The results are summarized in Table 2.

\section{Discussion}

Previous studies have shown that early treatment not only benefits infected people, but also protects the general population ${ }^{[7]}$. Treatment Manual in China (4th edition) was bring out and test \& treat strategy were implemented in 2016. But due to the individual

differences of patients, regimen options, drug adherence and the spread of drug-resistant strains, the therapeutic effect of some patients failed to meet expectations: failure or incomplete inhibition of virology, failure of immune reconstruction, increase of clinical risk diseases, etc ${ }^{[8-11]}$. virological indicators were be suggested and used as a monitoring index to diagnose and determine the failure of antiviral therapy. After 6 months of antiviral treatment, two consecutive plasma VL $>200$ copies $/ \mathrm{mL}$ was considered virological failure ${ }^{[12]}$. In the present study, we investigated 4424 cases treated in 2016 and found that $87.5 \%$ achieved positive therapy. If add cases whose viral loads remains stable after 18 months, the ratio would rise to $93.4 \%$, means $90 \%$ of the effective treatment targets can be achieved in Hunan, a central province in China. Among 292 patients who failed in treatment, there were three cases: 57 patients with low-level viral replication, 76 patients with high-level viral replication and 159 patients with inhibition succeeded initially, but the replication of the virus increased dramatically over time. It is important to point out that the current line of drug resistance detection for efficacy monitoring is $V L \geq$ 1000 copies $/ \mathrm{mL}$, and most analysis of influencing factors of virological failures were focused on this group. In fact, the low level of virus suppression is related to the rapid progress of HIV disease, 
cardiovascular complications and the rapid spread of HIV in the region ${ }^{[13-15]}$. So, the patients with lowlevel viral replication could not be ignored.

we compared the characteristics information and found that there were no significant differences in sex, clinic phases, average CD 4 cell counts baseline and dual infection between 5 groups $(P>0.05)$. The lack of HIV-VL baseline means that it was not possible to analyses the effect of initial viral replication, but not to our surprise, group 1 had the fast CD 4 cell conts growth, group 4 had the slowest growth rate, while in the fifth group, the CD4 cell counts decreased after the virus replication increased dramatically. Previous studies have shown that the increase in CD4 counts reaches a plateau after 4-6 years of viral response [16-17], this needs to be investigated further in our cohort. It looks like age, transmission mode and the interval between test and treat were significant different between 5 groups $(P<0.05)$. Patients in group 1 had the youngest age and the highest rate of test \& treat. Sexual transmission accounts for the highest proportion of all groups. Medication adherence was an important factor associated with low viral suppression proved by other study ${ }^{[18]}$, that's what we need to consider next. If look at the follow-up status, group 2 has the highest mortality rate while group 4 has the highest rate of loss of follow-up. These data imply a possibility that poor viral suppression can undermine confidence in continuing treatment. However, this needs to be investigated further.

Compared with group 3 and group 1, patients with the slighter clinical pahse had the better viral suppression effect. Compared with group 3 and group 2, males and those with lower CD 4 cell counts baseline $(<200 \mathrm{n} / \mu \mathrm{L})$ were more likely to had higher viral loads initially then decreased markedly. Compared with group 3 and group 5, patients transmitted by hetero sex were 5.494 times more likely to had lower viral loads initially then increased markedly than those transmitted by blood or mother-to-child $(O R=5.494, P=0.014)$, it was also possible happened for those with the slighter clinical pahse. To our surprise, compared with group 3 and group 4, gender, age, route of transmission, initial CD4 cell counts, marriage or not, co-infection and so forth did not differ between low and high levels of viral replication after treatment. In addition to host factors, virological factors deserve further studies, as the therapy effects depend on interaction between host, virus and drug.

\section{Conclusions}

In our study, CD 4 cell counts baseline under $500 \mathrm{n} / \mu \mathrm{L}$ and co-infected with HBV were independent risk factors for high HIV-1 replication. These were consistent with previous studies ${ }^{[19-20]}$. Young age and test \& treat were independent protective factors for viral suppression. These results imply that immune function, infection state, age and treatment time influence the therapeutic effects of HAART, and point out the importance of early treatment again, but screening for incomplete viral supression patients should be a routine practice in the management and control of HIV infection.

\section{Declarations}

\section{Ethics approval and consent to participate}


The data in this article are from the existing database of antiviral therapy in our province and the study has been approved by the Ethics Committee of Hunan Provincial Center for Disease Control and Prevention.

\section{Consent for publication}

Not applicable.

\section{Availability of data and material}

All data generated or analysed during this study are included in this published article.

\section{Competing interests}

The authors declare that they have no competing interests.

\section{Funding}

This work was funded by grants from Natural Science Foundation of Hunan Province (No. 2019JJ50298).

\section{Authors' contributions}

HE Jian-mei, ZHEN Jun and WEI Xiu-qing screened the targets from database. DING Li-sha and LI Xiangzhong made experimental index for patients. DING Li-sha analyzed and interpreted the data with CHEN Xi, and was a major contributor in writing the manuscript. All authors read and approved the final manuscript.

\section{Acknowledgements}

Not applicable.

\section{References}

1. De Cock KM, Gilks CF, Lo YR, Guerma T. Can antiretroviral therapy eliminate HIV transmission? Lancet. 2009; 373:7-9. 2. Cohen MS, Gay C, Kashuba AD, Blower S, Paxton L. Narrative review: antiretroviral therapy to prevent the sexual transmission of HIV-1. Ann Intern Med. 2007; 146(8):591-601. 3. Attia S, Egger M, Müller M, Zwahlen M, Low N. Sexual transmission of HIV according to viral load and antiretroviral therapy: systematic review and meta-analysis. AIDS. 2009; 23(11):1397-1404. 4. Montaner JS, Lima VD, Harrigan PR, Lourenço L, Yip B, Nosyk B, et al. Expansion of HAART coverage is associated with sustained decreases in HIV/AIDS morbidity, mortality and HIV transmission: the "HIV Treatment as Prevention" experience in a Canadian setting. PLoS One. 2014; 9(2):e87872. 5. Li QH, Gao YQ, Sun X, Liu Y, Ye JZ, Ji YX, et al. Clinical evaluation of highly active antiretroviral therapy in people living with HIV/AIDS. Chin J AIDS STD. 2008;14(4):354-356 6. Yao ZL, Su HY, Zhou J, Yin GZ, Yang XW, Zhang GL. 
Antiviral therapy for 148 cases of AIDS. Infect Dis Info. 2009; 22(6):359-361. 7. Sáez-Cirión A, Bacchus C, Hocqueloux L, Avettand-Fenoel V, Girault I, Lecuroux C, et al. Post-treatment HIV-1 controllers with a longterm virological remission after the interruption of early initiated antiretroviral therapy ANRS VISCONTI Study. PLoS Pathog. 2013; 9(3): e1003211. 8. Mezzaroma I, Carlesimo M, Pinter E, Muratori DS, Di Sora F, Chiarotti F, et al. Clinical and immunologic response without decrease in virus load in patients with AIDS after 24 months of highly active antiretroviral therapy. Clin Infect Dis. 1999; 29(6):1423-1430. 9. Torti C, Quiros-Roldan E, Scudeller L, Lo Caputo S, Tomasoni L, Castelli F, et al. Characterization of viroimmunological responses in a closely followed cohort of heavily pretreated patients: evidence from the GenPheRex Study. HIV Med. 2003; 4(3):263-270. 10. Sufka SA, Ferrari G, Gryszowka VE, Wrin T, Fiscus SA, Tomaras GD, et al. Prolonged CD4+ cell/virus load discordance during treatment with protease inhibitorbased highly active antiretroviral therapy: immune response and viral control. J Infect Dis. 2003; 187(7):1027-1037. 11. Mellors JW1, Rinaldo CR Jr, Gupta P, White RM, Todd JA, Kingsley LA. Prognosis in HIV-1 infection predicted by the quantity of virus in plasma. Science. 1996; 272(5265):1167-1170. 12. Hirschhorn L, Beattie A, Davidson D, et al. The role of viral load as a measure of the quality of care for people with HIV: the expert meeting report. 2005. 13. Skarbinski J, Rosenberg E, Paz-Bailey G, Hall HI, Rose $\mathrm{CE}$, Viall AH, et al. Human immunodeficiency virus transmission at each step of the care continuum in the United States. JAMA Intern Med. 2015; 175(4):588-596. 14. Langford SE, Ananworanich J, Cooper DA. Predictors of disease progression in HIV infection: a review. AIDS Res Ther. 2007; 14(4):11. 15. FACT SHEET: The national HIV/AIDS strategy: updated to 2020. whitehouse.gov.

2015https://www.whitehouse.gov/the press ofce/2015/07/30/fact sheet national hivaids strategy updated 2020. Accessed June 2017. 16. Kabugo C, Bahendeka S, Mwebaze R, Malamba S, Katuntu D, Downing $\mathrm{R}$, et al. Long-term experience providing antiretroviral drugs in a fee-for-service HIV clinic in Uganda: evidence of extended virologic and CD4+ cell count responses. J Acquir Immune Defic Synder. 2005; 38(5): 578-583 17. Le Moing V, Thiébaut R, Chêne G, Sobel A, Massip P, Collin F, et al. Long-term evolution of CD4 count in patients with a plasma HIV RNA persistently $<500$ copies/mL during treatment with antiretroviral drugs. HIV Med. 2007; 8(3):156-163 18. Nsubuga-Nyombi T, Sensalire S, Karamagi E, Aloyo J, Byabagambi J, Rahimzai M, et al. Multivariate analysis of covariates of adherence among HIV positive mothers with low viral suppression. AIDS Res Ther. 2018; 15(1):9. 19. Siddhi Mankame, Negin Niknam, Mohammed Elfekey, Rebecca Schwartz, Rehana Rasul, Bruce Hirsch, et al. When Viral Suppresion Is Not Enough: Clinical Characteristics of HIV Infected Patients with Poor Immune Recovery. Open Forum Infect Dis. 2017 Fall; 4Suppl 1: S212. 20. Maponga TG, Andersson MI, van Rensburg CJ, Arends JE, Taljaard J, Preiser W, et al. HBV and HIV viral load but not microbial translocation or immune activation are associated with liver fibrosis among patients in South Africa. BMC Infect Dis. 2018; 18(1): 214.

\section{Tables}

Due to technical limitations, tables 1 and 2 are only available as a download in the supplemental files section. 
Figures

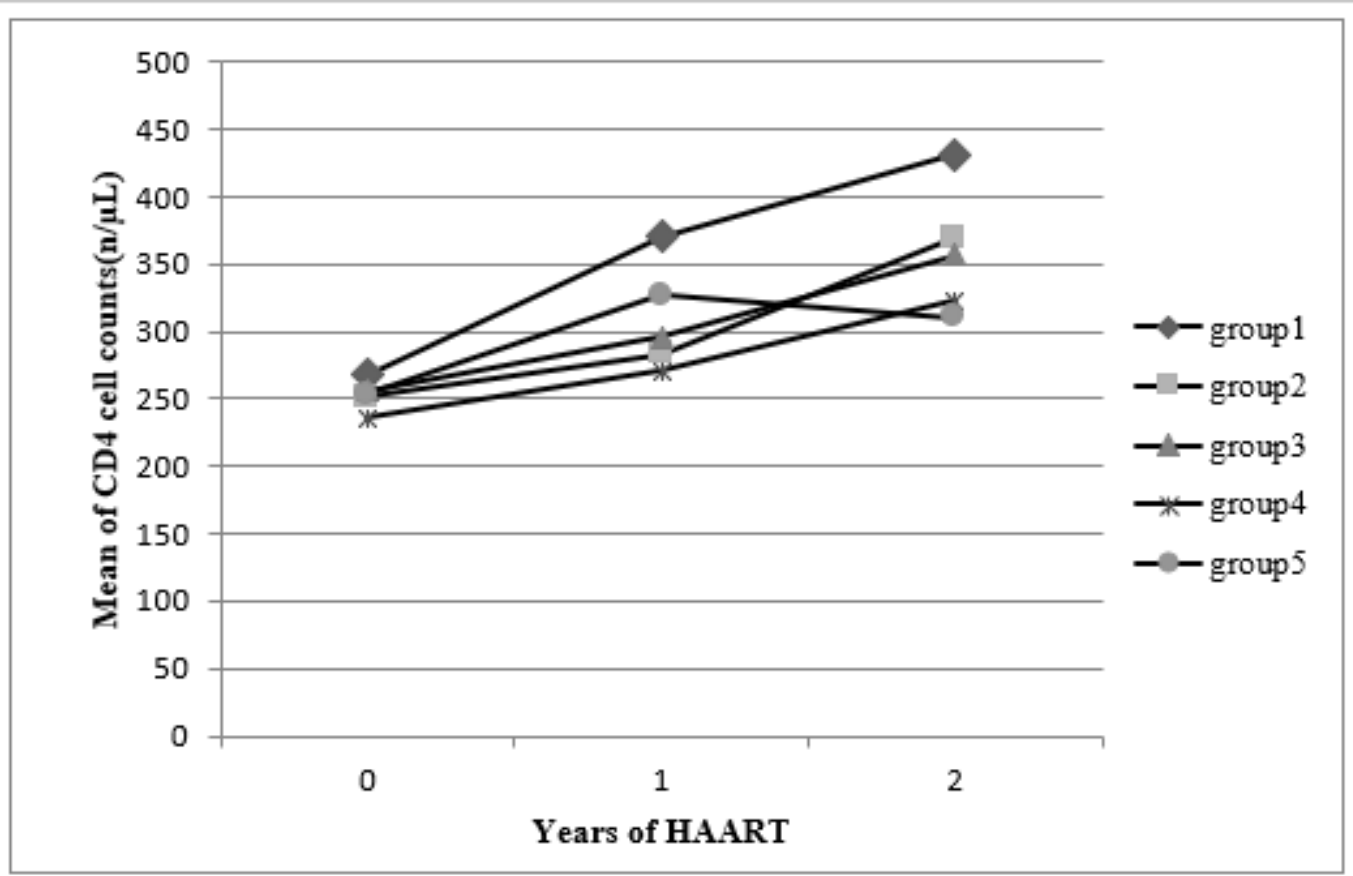

Fig 1 Rising trends of CD4 cell counts among 5 groups

Figure 1

Rising trends of CD4 cell counts among 5 groups

\section{Supplementary Files}

This is a list of supplementary files associated with this preprint. Click to download.

- Tables1and2.pdf 